\title{
Obesity in West Virginia: Control and Costs
}

\author{
Janaranjana Herath ${ }^{1, *}$, Cheryl Brown ${ }^{2}$ \\ ${ }^{1}$ Tillman School of Business, Mount Olive College, Mount Olive, North Carolina, USA \\ ${ }^{2}$ Davis College of Agriculture, Natural Resources and Design, West Virginia University, Morgantown, USA \\ *Corresponding author: sbandara@moc.edu
}

Received September 02, 2013; Revised November 01, 2013; Accepted November 06, 2013

\begin{abstract}
West Virginia reports a high obesity rate, and the prevalence of obesity is 8 percent higher than the national rate. Obesity is linked with several health diseases, certain psychological disorders, quality of life, premature deaths as well as healthcare costs. Prevention of obesity is a must and changing behavioral factors is one way of controlling obesity. This research study attempts to examine the potential use of physical exercise and fewer calorie intakes in controlling obesity, and to estimate costs of obesity in West Virginia using Behavioral risk Factor Surveillance System data of 2001 and 2009. Three logit equations were used in the analysis. Results reveal that potential of using physical exercise in controlling obesity in West Virginia has increased from 2001 to 2009, though the desire of engaging in physical exercise of obese people has decreased. However, the willingness of taking fewer calories of obese individuals has increased significantly from 2001 to 2009. The cost estimations indicate that direct medical cost of obesity and total costs associated with obesity have increased by $\$ 51$ million and $\$ 704$ million respectively from 2001 to 2009.
\end{abstract}

Keywords: logit analysis, obesity, calorie intake, cost of obesity, physical exercise

Cite This Article: Janaranjana Herath, and Cheryl Brown, "Obesity in West Virginia: Control and Costs." American Journal of Public Health Research 1, no. 8 (2013): 203-208. doi: 10.12691/ajphr-1-8-2.

\section{Introduction}

Obesity is a major health problem in the United States. Approximately, 34 percent of the U.S. adult population is obese, which is over 72 million people ([1]. If the current trend of obesity continues, 50 percent of the U.S. population will be obese in 2030 [2]. Obesity is linked with several diseases like heart disease, diabetes (type II), hypertension, cancer, arthritis, asthma, and some psychological disorders [3]. Overweight and obesity account for approximately 20 percent of all cancer cases [4]. Obesity has a major influence upon the development of CVD, and this affects physical and social functioning, and the quality of life [5]. The prevalence of diabetes (type II) continued to increase with increasing obesity in USA [6]. There is a significant relationship between obesity and asthma, especially among children [7]. The relationship between obesity and hypertension is complex [8]. Arthritis rates increase with higher body weights, and obese individuals are more likely to report doctordiagnosed arthritis than normal weight individuals [9]. Obesity increases the risk of premature mortality [10] and nearly 300,000 annual deaths are associated with obesity in the United States [11]. It degrades the quality of life by limiting mobility, physical endurance, social, academic and job participation [12].

Economic losses associated with obesity are high. In 1998, the United States spent $\$ 78.5$ billion in medical costs related to obesity [13]. According to the U.S. Department of Health and Human Services [14], the yearly cost of obesity was $\$ 147$ billion in the year 2008 and people who were obese had medical costs that were $\$ 1,429$ higher than the cost for people of normal body weight. The overall annual cost of being obese is $\$ 2,646$ for an obese man and $\$ 4,879$ for an obese woman [2].

\subsection{Controlling Obesity}

Engaging in physical exercise mitigates obesity. For instance, a sustained 10 percent weight loss reduces an overweight person's lifetime medical costs by $\$ 2,200$ to $\$ 5,300$ by lowering costs associated health diseases [15]. Nearly $\$ 77$ billion direct medical cost can be prevented annually by increasing regular exercises among the inactive Americans (about 88 million) over 15 years of age [16]. The aspects of the home, school, work and community environments all influence level of physical exercise as an individual [17]. Women are less active than men. African-Americans, Hispanics, and others of lower income status also engage less in physical exercise [18]. Many states are addressing physical exercise issues with statewide action plans, interagency cooperation efforts and health department initiatives. Severely obese people can reduce their weight through lifestyle change and moderate-intensity bodily exercise [19].

In overcoming severe obesity, diet, physical exercise, and behavioral modifications are recommended, which result in five to ten percent weight loss in the short term [17]. Vegetarian diets provide high protection against obesity [20]. Sedentary lifestyles and high-fat energydense diets are the fundamental causes of obesity [21]. Higher education lowers obesity rates as health promotion 
occurs through dissemination of knowledge [22]. More physical education (PE) classes in schools on youth decreased the probability of students' overweight [23]. Rural poverty and lack of resources, especially in certain pockets of rural areas relate with obesity [24].

The objectives of this study are to examine the potential use of physical exercise and low calorie intake in controlling obesity and to estimate the cost associated with obesity in West Virginia.

The paper is organized into six sections. Section 2 provides background information of West Virginia. Section 3 explains methodology and data sources. Section 4 discusses empirical results and analysis. Section 5 presents conclusions and suggestions.

\section{Background of the Study Area}

The total population of West Virginia is about 1.85 million; 56 percent live within urban areas while the rest lived in rural areas [25]. Nearly 79 percent of the populations are adults and 51 percent of them are female. Of the total population, 94 percent are the white and 3.4 percent are African Americans. West Virginia reports significantly high poverty rate, especially in rural areas [24]. The annual per capita personal income was $\$ 32,219$ in 2009, which was 17.7 percent below the national per capita income of $\$ 39,138$ [26].

About 33.5 percent of adults in West Virginia are obese, and it is 8 percent higher than the national average rate [27]. This higher obesity rate is associated with factors like, no leisure-time physical exercise, less consumption of fruits and vegetables, and more consumption of soda, and other factors causing chronic diseases [28]. Lack of education, less availability of food stores, higher commuting time, low income, and built environment are some factors that could affect obesity in West Virginia [29]. Obesity damages the economy of West Virginia [27]. For instance, medical costs associated with adult obesity alone were 500 million dollars in 2003.

\section{Methodology}

Obesity can be assumed as a function of an individual's energy balance which is the difference between calorie intake and expenditure for a particular time period. In the context of [30] household production theory of consumer behavior, obesity can be considered as the byproduct of other goals of an individual's utility function [31]. Thus, Becker provides a framework for examining the issues of calorie intake and expenditure with the recognition of a rational consumer who uses goods and services purchased at the market, together with his or her own time to produce more commodities that enter his or her utility function. Health is one of these commodities that depend partly on the consumption of appropriate diet and engaging in physical exercise in the intention of weight gain control.

To control weight gain an individual can reduce calorie consumption and/or can engage in physical exercise. Thus, to analyze the potential use of those, three logit equations are used with the dependent variables of caloric intakes, physical exercise, and obesity as follows:

$$
\mathrm{RC}_{\mathrm{i}}=\mathrm{f}\left(\mathrm{OB}_{\mathrm{i}}, \mathrm{PA}_{\mathrm{i}}, \mathrm{D}_{\mathrm{ji}}, \mathrm{SF}_{\mathrm{i}}, \mathrm{EF}_{\mathrm{i}}, \mathrm{BF}_{\mathrm{i}}\right)
$$

$$
\begin{aligned}
& \mathrm{PA}_{\mathrm{i}}=\mathrm{g}\left(\mathrm{OB}_{\mathrm{i}}, \mathrm{RC}_{\mathrm{i}}, \mathrm{D}_{\mathrm{ji}}, \mathrm{SF}_{\mathrm{i}}, \mathrm{EF}_{\mathrm{i}}, \mathrm{BF}_{\mathrm{i}}\right) \\
& \mathrm{OB}_{\mathrm{i}}=\mathrm{h}\left(\mathrm{RC}_{\mathrm{i}}, \mathrm{PA}_{\mathrm{i}}, \mathrm{D}_{\mathrm{ji}}, \mathrm{SF}_{\mathrm{i}}, \mathrm{EF}_{\mathrm{i}}, \mathrm{BF}_{\mathrm{i}}\right) .
\end{aligned}
$$

The first dependent variable, $\mathrm{RC}_{\mathrm{i}}$, reflects the decision of individual $i$, to reduce his or her caloric intake, which appears as a binary choice, where $\mathrm{RC}_{\mathrm{i}}$ is equal to 1 , if individual $\mathrm{i}$, has decided to reduce calories and equals to zero otherwise. The second dependent variable $\mathrm{PA}_{\mathrm{i}}$, represents whether an individual, $\mathrm{i}$, engages in physical exercise or not. If the individual engages in physical exercise (except what $\mathrm{s} /$ he does in his her normal job) $\mathrm{PA}_{\mathrm{i}}$ equals to 1 , or otherwise 0 . The third dependent variable, $\mathrm{OB}_{\mathrm{i}}$ is whether an individual $\mathrm{i}$ is obese or not and if obese, $\mathrm{OB}_{\mathrm{i}}$ equals to 1 , otherwise 0 . Independent variable $\mathrm{D}_{\mathrm{ji}}$ represents the $\mathrm{j}^{\text {th }}$ disease of the $\mathrm{i}^{\text {th }}$ individual, which appears as a qualitative variable equals to 1 , if the individual has the disease and 0 otherwise. Disease $\mathrm{j}$ goes from 1 to 4 for asthma, heart disease, arthritis, diabetics, and cancer. $\mathrm{SF}_{\mathrm{i}}, \mathrm{BF}_{\mathrm{i}}$, and $\mathrm{EF}_{\mathrm{i}}$ are socioeconomic factors, other behavioral factors, and environmental factors, which are specified in everyone.

The estimated equations can be shown as:

$$
\begin{aligned}
\mathrm{RC}_{\mathrm{i}}= & \alpha_{0 \mathrm{C}}+\alpha_{1 \mathrm{C}} \mathrm{OB}_{\mathrm{i}}+\alpha_{2 \mathrm{C}} \mathrm{PA}_{\mathrm{i}}+\alpha_{3 \mathrm{C}} \mathrm{D}_{\mathrm{ji}} \\
& +\sum \psi \mathrm{SF}_{\mathrm{i}}+\sum \delta \mathrm{EF}_{\mathrm{i}}+\sum \omega \mathrm{BF}_{\mathrm{i}} . \\
\mathrm{PA}_{\mathrm{i}}= & \alpha_{0 \mathrm{PA}}+\alpha_{1 \mathrm{PA}} \mathrm{OB}_{\mathrm{i}}+\alpha_{2 \mathrm{PA}} \mathrm{RC}_{\mathrm{i}}+\alpha_{3 \mathrm{PA}} \mathrm{D}_{\mathrm{ji}} \\
& +\sum \psi \mathrm{SF}_{\mathrm{i}}+\sum \delta \mathrm{EF}_{\mathrm{i}}+\sum \omega \mathrm{BF}_{\mathrm{i}} . \\
\mathrm{OB}_{\mathrm{i}}= & \alpha_{0 \mathrm{O}}+\alpha_{10} \mathrm{RC}_{\mathrm{i}}+\alpha_{2 \mathrm{O}} \mathrm{PA}_{\mathrm{i}}+\alpha_{30} \mathrm{D}_{\mathrm{ji}} \\
& +\sum \psi \mathrm{SF}_{\mathrm{i}}+\sum \delta \mathrm{EF}_{\mathrm{i}}+\sum \omega \mathrm{BF}_{\mathrm{i}} .
\end{aligned}
$$

where $\alpha_{0}$ is the intercept value of each equation, $\alpha_{1}$ and $\alpha_{2}$ values are the coefficients of each endogenous variable while $\psi, \delta$, and $\omega$ are coefficients of socioeconomic, behavioral, and environmental factors.

\subsection{Types and Sources of Data}

Behavior Risk Factor Surveillance Systems (BRFSS) survey data for years 2001 and 2009 were the main sources of data [32,33]. BRFSS is a survey of health-risk behaviors in non-institutionalized civilian adults, age 18 years and over. These data were collected from a stratified random sample through computer-assisted telephone interviewing by state health departments with the collaboration of the Center for Disease Control and Prevention (CDC). Interviewers were given an additional training on BRFSS questionnaire and procedures before the work. Interviewers were systematically monitored a certain amount of time each month. Interviews were conducted during each calendar month on week days, weekends, daytime as well as evenings following the standard procedures of an interview.

Data on obesity, diseases, socioeconomic factors, behavioral factors and environmental factors were collected from BRFSS Survey of CDC in 2001 and 2009. Missing data reported on BMI, calorie intake, physical exercise, income and any of the variables were dropped from the sample. Moreover, data on reported pregnant women were not considered in the analysis. Finally, a sample of 2551 individuals for 2001 and a sample of 1996 
individuals for 2009 were used. Statistical software of STATA 9.1 was used for analyses [34].

In cost calculation related to obesity, estimations of Dor et al. [2], Tasi et al. [35] and Finkelstein et al. [1,36] are mainly used. Those estimations are based on almost all obesity relate studies, which provide fair estimations for reference.

The variables used for analysis with their mean values, and standard deviations are presented in Table 1.
According to the Table, obesity has increased by 7 percent from 2001 to 2009 while rate of overweight has decreased from 38 to 36 percent. The individuals engage in physical exercise have reduced about 10 percent from 2001 to 2009. Decision of reducing calorie intake shows an increase of 3 percent from 2001 to 2009. The percentage of individuals having diabetes, heart diseases, and arthritis indicate significantly high values for 2009 compared to 2001. Alcohol consumption reports 19 percent higher in 2009.

Table 1. Definitions of variables used for analyses with their summary statistics

\begin{tabular}{|c|c|c|c|}
\hline Variable & \multirow{2}{*}{ Description } & $\mathbf{2 0 0 1}$ & $\mathbf{2 0 0 9}$ \\
\cline { 3 - 4 } & Mean & Mean \\
\hline Obesity [OB] & 1 if obese; 0 otherwise & 0.2512 & 0.3249 \\
\hline Physical exercise [PA] & 1 if engage in physical exercise; 0 otherwise, in last 30 days & 0.6828 & 0.5823 \\
\hline Reduced Calorie intake [RC] & 1 if reduce calorie intake; 0 otherwise & 0.6805 & 0.7175 \\
\hline Gender & 1 if male; 0 otherwise & 0.4241 & 0.4096 \\
\hline Age & In years & 49.372 & 53.027 \\
\hline Edu & 1 if learned up to high school or more than high school; 0 otherwise & 43.2 & 50.121 \\
\hline Income & Annual household income in dollars & 35117 & 36248 \\
\hline Smoke & 1 if smokes; 0 otherwise & 0.2849 & 0.1871 \\
\hline Alcohol & 1 if take alcohol; 0 otherwise & 0.3394 & 0.5254 \\
\hline Diabetes & 1if diabetic; 0 otherwise & 0.0929 & 0.2504 \\
\hline Heart Diseases & 1 if heart diseases; 0 otherwise & 0.1403 & 0.1372 \\
\hline Asthma & 1 if suffers from asthma; 0 otherwise & 0.1274 & 0.1362 \\
\hline Cancer & 1 if suffers from a cancer; 0 otherwise & - & 0.1866 \\
\hline Arthritics & 1 if suffers from Arthritics; otherwise & 0.3284 & 0.5521 \\
\hline Sleepless & Days of sleepless in the previous month & - & 9.2984 \\
\hline
\end{tabular}

\section{Results and Discussion}

\subsection{Examine the Potential Use of Physical Exercise and Fewer Calorie Intake in Controlling Obesity}

\subsubsection{Logit Analyses}

The logit estimations for obesity, physical exercise, and reduced calorie intake for 2001 and 2009 are presented in Table 2, Table 3 and Table 4. Marginal effects of each estimation $(\mathrm{dy} / \mathrm{dx})$, standard error, and $\mathrm{p}$-value are presented in the Tables.

Table 2. Logit regression results: marginal effects for obesity

\begin{tabular}{|c|c|c|c|c|c|c|}
\hline \multirow[b]{2}{*}{ Variable } & \multicolumn{3}{|c|}{2001} & \multicolumn{3}{|c|}{2009} \\
\hline & $d y / d x$ & Std. Err. & $\mathbf{P}>|\mathbf{z}|$ & $d y / d x$ & Std. Err. & $\mathbf{P}>|\mathbf{z}|$ \\
\hline Physical exercise & $-0.0747^{* * *}$ & 0.020 & 0.00 & $-0.1402^{* * *}$ & 0.025 & 0.00 \\
\hline Reduced Calories & -0.0218 & 0.019 & 0.25 & 0.0268 & 0.0270 & 0.32 \\
\hline Age & $0.0176^{* * *}$ & 0.003 & 0.00 & $0.0084 *$ & 0.005 & 0.09 \\
\hline $\mathrm{Age}^{2}$ & $-0.0002^{* * *}$ & 0.000 & 0.00 & $-0.0001^{* * *}$ & 0.000 & 0.00 \\
\hline Income & $-0.0001^{*}$ & 0.000 & 0.10 & 0.0001 & 0.000 & 0.44 \\
\hline Edu & 0.0037 & 0.024 & 0.87 & 0.0366 & 0.032 & 0.25 \\
\hline Smoke & $-0.0819 * * *$ & 0.018 & 0.00 & $-0.1803 * * *$ & 0.027 & 0.00 \\
\hline Alcohol & $0.0472 * * *$ & 0.018 & 0.01 & -0.001 & 0.024 & 0.95 \\
\hline Diabetes & $0.3101^{* * *}$ & 0.037 & 0.00 & $0.2117^{* * *}$ & 0.028 & 0.00 \\
\hline Asthma & $0.1070 * * *$ & 0.028 & 0.00 & $0.0814 * *$ & 0.036 & 0.02 \\
\hline Arthritis & $0.0732 * * *$ & 0.020 & 0.00 & $0.1419^{* * *}$ & 0.025 & 0.00 \\
\hline Cancer & - & - & & 0.0035 & 0.031 & 0.91 \\
\hline \multirow[t]{2}{*}{ Heart diseases } & -0.0066 & 0.026 & 0.80 & -0.0610 & 0.126 & 0.62 \\
\hline & \multicolumn{3}{|c|}{$\begin{array}{c}\mathrm{N}=2551 \text {; Prob }>\text { chi2 }=0.0000 ; \\
\text { Log likelihood = }-1315.74 ; \text { LR chi2(12) = 244.66; } \\
\text { Pseudo R2 }=0.09\end{array}$} & \multicolumn{3}{|c|}{$\begin{array}{c}\mathrm{N}=1996 ; \text { Prob }>\text { chi2 }=0.0000 ; \\
\quad \text { Log likelihood = -1195.86; } \\
\text { LR chi2(13) = 328.83; Pseudo R2 = } 0.12\end{array}$} \\
\hline
\end{tabular}

, **, * are significant @ 1\%, 5\% and 10\% respectively

Table 2, Logit analysis for obesity shows that most of the variables for 2001, and 2009 are statistically significant with the expected signs. The significant and negative sign for physical exercise indicates that individuals who are more likely to engage in physical exercise are less likely to be obese. Importantly, results indicate that the percentage of individuals doing physical exercise; less likely to get obese become double in 2009 compared to 2001. This implies the importance and potential use of physical exercise to control obesity. Age indicates nonlinear effects on obesity. Income shows negative relationship with physical exercise, but the impact is low. Smokers are less likely to become obese, and it is 8 and 18 percent in 2001 and 2009 respectively. However, Smoking habit is associated with some obesityrelated diseases like cancer and heart diseases even though 
literature is limited related to the link of obesity and smoking [37]. Alcohol consumption is assumed to be a risk factor for obesity [38], and empirical results only for 2001 support the argument. Individuals suffering from diabetes were 31 percent more likely to getting obese in 2001 and 21 percent in 2009. Interestingly, the potentials of being obese of diabetic patients are reduced by 10 percent from 201 to 2009. This may be due to better healthcare services within the last eight years. Individuals suffering from asthma indicate about 10 percent more likely of getting obese, both in 2001 and 2009. Those who report arthritis are more likely of getting obese and it is 7 percent for 2001 and 14 percent for 2009. It is a 7 percent increase, and it may be due to be the high number of arthritis patients, sedentary jobs, or any other reduces physical exercise. Education does not indicate significant relations with obesity both in 2001 and 2009 even though the reduction of obesity with more education was proven to be true in many studies [22,23,39].

Table 3. Logit regression results: marginal effects for physical exercise

\begin{tabular}{|c|c|c|c|c|c|c|}
\hline \multirow{2}{*}{ Variable } & \multicolumn{3}{|c|}{2001} & \multicolumn{3}{|c|}{2009} \\
\hline & $d y / d x$ & Std. Err. & $\mathbf{P}>|\mathbf{z}|$ & $d y / d x$ & Std. Err. & $\mathbf{P}>|\mathbf{z}|$ \\
\hline Obesity & $-0.0917 * * *$ & 0.023 & 0.00 & $-0.1383^{* * *}$ & 0.025 & -0.00 \\
\hline Reduced Calories & $0.1135^{* * *}$ & 0.021 & 0.00 & 0.0001 & 0.024 & 0.99 \\
\hline Age & $-0.0064 * *$ & 0.003 & 0.04 & -0.0001 & 0.004 & 0.98 \\
\hline Age $^{2}$ & $0.0006^{* *}$ & 0.000 & 0.04 & 0.0000 & 0.000 & 0.42 \\
\hline Edu & $0.1544^{* * *}$ & 0.027 & 0.00 & $0.1101^{* * *}$ & 0.031 & 0.00 \\
\hline Income & $0.0002 * * *$ & 0.000 & 0.00 & $0.0003^{* * *}$ & 0.000 & 0.00 \\
\hline Smoke & $-0.0605 * * *$ & 0.022 & 0.01 & $-0.0952 * * *$ & 0.031 & 0.00 \\
\hline Alcohol & $0.0846^{* * *}$ & 0.020 & 0.00 & 0.0023 & 0.023 & 0.92 \\
\hline Diabetes & -0.0310 & 0.034 & 0.36 & $-0.0630 * *$ & 0.027 & 0.02 \\
\hline Asthma & -0.0367 & 0.028 & 0.20 & -0.0012 & 0.034 & 0.97 \\
\hline Cancer & - & - & - & 0.0387 & 0.029 & 0.19 \\
\hline Arthritics & -0.0340 & 0.021 & 0.11 & -0.0339 & 0.024 & 0.16 \\
\hline \multirow[t]{2}{*}{ Heart diseases } & -0.0466 & 0.029 & 0.11 & -0.0960 & -0.118 & 0.44 \\
\hline & \multicolumn{3}{|c|}{$\begin{array}{c}\mathrm{N}=2551 ; \text { Prob }>\text { chi2 = 0.0000; } \\
\text { Log likelihood = -1465.49; LR chi2 }(12)=256.16 ; \\
\text { Pseudo R2 = 0.0804 }\end{array}$} & \multicolumn{3}{|c|}{$\begin{array}{c}\mathrm{N}=1996 ; \text { Prob }>\text { chi2 }=0.0000 ; \\
\quad \text { Log likelihood = -1275.28; } \\
\text { LR chi2(13) = 162.33; Pseudo R2 = } 0.0598\end{array}$} \\
\hline
\end{tabular}

***, **, * are significant @ 1\%, 5\% and 10\% respectively

Table 4. Logit regression results: marginal effects for reduced calorie intake

\begin{tabular}{|c|c|c|c|c|c|c|}
\hline & \multicolumn{3}{|c|}{2001} & \multicolumn{3}{|c|}{2009} \\
\hline Variable & $\mathrm{dy} / \mathrm{dx}$ & Std. Err. & $\mathrm{P}>|\mathrm{z}|$ & $\mathrm{dy} / \mathrm{dx}$ & Std. Err. & $\mathrm{P}>|\mathrm{z}|$ \\
\hline Physical exercise & $0.1142 * * *$ & 0.021 & 0.00 & 0.0011 & 0.022 & 0.96 \\
\hline Obesity & -0.0271 & 0.023 & 0.24 & $0.0668 * * *$ & 0.023 & 0.00 \\
\hline Age & $0.0156^{* * *}$ & 0.003 & 0.00 & 0.0047 & 0.004 & 0.27 \\
\hline Age2 & $-0.0002 * * *$ & 0.000 & 0.00 & $-0.0007^{* *}$ & 0.000 & 0.05 \\
\hline Income & $-0.0001 * *$ & 0.000 & 0.03 & -0.0004 & 0.000 & 0.47 \\
\hline Edu & $0.0656^{* * *}$ & 0.028 & 0.01 & -0.0091 & 0.029 & 0.75 \\
\hline Smoke & $-0.0778 * * *$ & 0.022 & 0.00 & -0.0384 & 0.030 & 0.20 \\
\hline Alcohol & $-0.0459 * *$ & 0.021 & 0.03 & $0.1105^{* * *}$ & 0.021 & 0.00 \\
\hline Diabetes & $0.0963^{* * *}$ & 0.031 & 0.01 & $0.0969 * * *$ & 0.024 & 0.00 \\
\hline Asthma & 0.0401 & 0.027 & 0.14 & 0.0345 & 0.031 & 0.27 \\
\hline Cancer & - & - & & 0.0005 & 0.028 & 1.00 \\
\hline Arthritis & 0.0145 & 0.021 & 0.50 & -0.0261 & 0.023 & -0.25 \\
\hline \multirow[t]{2}{*}{ Heart diseases } & $0.0804^{* * *}$ & 0.027 & 0.01 & $0.3284^{* * *}$ & 0.131 & 0.01 \\
\hline & \multicolumn{3}{|c|}{$\begin{array}{c}\mathrm{N}=2551 ; \text { Prob }>\text { chi2 }=0.0000 ; \\
\quad \text { Log likelihood = -1514.61; } \\
\text { LR chi2(12) = 167.07; Pseudo R2 = } 0.0523\end{array}$} & \multicolumn{3}{|c|}{$\begin{array}{c}\mathrm{N}=1996 ; \text { Prob }>\text { chi2 = } 0.000 \\
\text { Log likelihood = -12227.94; } \\
\text { LR chi2(13) = 328.83; Pseudo R2 = } 0.041\end{array}$} \\
\hline
\end{tabular}

***,**,* are significant @ 1\%,5\% and 10\% respectively

Logit analysis for physical exercise is shown in Table 3. Obese individuals are less likely to engage in physical exercise; and it is 9 percent in 2001 and 14 percent in 2009. This may be due to sedentary jobs, lack of recreational facilities, more commuting time or any other related to obese individuals. The result for reduce calorie intake for 2001 indicates that those who decide to take low calories are 11 percent more likely to engage in physical exercise for weight gain control 2001. However, the empirical result for 2009 does not show significant impacts. As expected, age indicates a negative relationship with physical exercise, but the impact is low. The education indicates a positive relationship with physical exercise for both 2001 and 2009. Individuals who completed high school or more are 15 percent more likely engage in physical exercise in 2001. The value becomes 11 percent in 2009. Results imply the potential use of education to improve physical exercise, which reduces obesity subsequently. Household annual income indicates a positive relationship, but the impact is low. Smokers 
seem to be less likely to do physical exercise in both years. Except diabetes in 2009, individuals suffering from asthma, arthritis, cancer or heart diseases do not show any significant results with physical exercise.

Table 4 indicates the results for reduced calorie intake (dependent variable is defined as 1 if reduce calorie intake; 0 otherwise). The results for 2001 shows that individuals engaged in physical exercise are 11 percent more likely to have low calorie intake compared to 2009. Obese individuals in 2009 are 7 percent more likely to reduce calorie intake compared to non-obese individuals. This indicates the potential use of calorie intake to control obesity. Increasing age seems to be reducing calorie intake as expected. Alcohol consumption indicates a mixed impact on low calorie intake. As expected, individuals who report diabetes are more likely to take low calories for better health gains. Also, individuals suffering from heart diseases are more likely to reduce calorie intake.

\subsection{Estimating Costs of Obesity in West Virginia}

In estimating costs of obesity and its changes from 2001 to 2009, a few studies were used as in Table 5 [1,2,35,36].

Using all the published papers on cost calculation related to obesity before June 2010, and using appropriate inflation effect, Dor et al. [2] estimated the total cost of obesity for 2009. In addition to the individual cost, other indirect costs of lost wages, the value of missing life, gasoline cost and cost of life insurance were considered in estimating the annual costs. According to the study, the overall, total annual costs of being obese are $\$ 4879$ for an obese woman and $\$ 2646$ for an obese man. Overall costs of being overweight are \$524 and \$432 for a woman and a man, respectively. These values are assumed as the values for West Virginia to estimate total cost of West Virginia in 2001 and 2009.

Tsai et al. [35] calculated direct medical cost of overweight and obesity in the United States reviewing 33 US studies published between 1992 and 2008. Using the four highest-quality national-level studies with appropriate adjustments to reflect inflation, changes in gender, age, and weight distributions, the study [35] estimated the direct medical cost of overweight and obesity per an average individual for 2008 as \$266 and \$1723 respectively.

Finkelstein et al. [1,36] revealed that obesity- related costs increased by 24 percent from 2001 to 2009; this was higher than the medical care consumer price index over that time period. Assuming this increase was evenly distributed over these years, it was 3 percent per year. This percentage was used to adjust the individual obesity values for 2001 and 2009 as presented in Dor et al. and Tasi et al.

Table 5. Costs of obesity in West Virginia (2001 and 2009)

\begin{tabular}{|c|c|c|c|c|}
\hline Study & & From studies & Estimated for 2001 & Estimated for 2009 \\
\hline $\begin{array}{c}\text { *Tsai et al. (2010) } \\
\text { Direct medical cost/person (2008) }\end{array}$ & Obesity & $\$ 266$ & $\$ 218$ & $\$ 274$ \\
\hline \multirow[t]{2}{*}{$\begin{array}{c}* \text { Dor et al. }(2010) \\
\text { Total cost/person }(2009)\end{array}$} & Obesity (women) & $\$ 4,879$ & $\$ 3,854$ & $\$ 4,879$ \\
\hline & Obesity (men) & $\$ 2,646$ & $\$ 2,090$ & $\$ 2,646$ \\
\hline & & & 2001 & 2009 \\
\hline \multicolumn{3}{|c|}{ Obese women population in West Virginia (18 \& over) } & 179,860 & 237,501 \\
\hline \multicolumn{3}{|c|}{ Direct Medical Cost of obesity } & $\$ 76,881,188$ & $\$ 127,598,512$ \\
\hline \multicolumn{3}{|c|}{ Total Cost of obesity } & $\$ 1,054,344,380$ & $\$ 1,762,549,914$ \\
\hline
\end{tabular}

Table 5 indicates the results for cost calculations. Statewide medical cost and overall costs of obesity for West Virginia were estimated by multiplying the per person costs times the adult obese population. For direct medical costs this resulted $\$ 77$ million for 2001 and $\$ 125.5$ million for 2009. These are a \$51 million or a 66 percent increase over that time. Overall costs or the total costs of obesity were $\$ 1,054$ million for 2001 and $\$ 1,762$ for 2009; a $\$ 708$ million or a 40 percent increase from 2001 to 2009. Thus, results indicate a rapid increment of costs of obesity in West Virginia.

Total healthcare expenditures of West Virginia for 2009 were $\$ 13,964$ million [40]. If the costs of obesity are compared with these expenditures, direct medical cost of obesity is about 1 percent, but total cost of obesity is 12.6 percent of total healthcare expenditures.

\section{Conclusions and Policy Implications}

This study has two parts. First, it examines the relationship between obesity, physical exercise and reduced calorie intake; using Logit estimations for 2001 and 2009. Second, the study calculates costs of obesity in
West Virginia. The results lead to a few important conclusions.

The study reveals that the percentage of individuals doing physical exercise; less likely to get obese become double in 2009 compared to 2001. Thus, the percentage of being obese has decreased significantly with engaging in more physical exercise. This implies the potential use of physical exercise to control obesity in West Virginia. As education significantly improves the desire on engaging physical exercise, programs to enhance knowledge on obesity, obesity-related diseases, and healthcare would be more benefited.

The study shows that obese adults are getting less likely to engage in physical exercise, while obese population got increased from 2001 to 2009. This implies the less room for using physical exercise to reduce the weight gain among obese people. However, the study reveals that the desire of low calorie intake of obese individuals has increased from 2001 to 2009. Thus, enhancing more educational and promotional programs for reducing calorie intake would be more practicable for obese individuals. Also programs for healthier food intakes would be benefited. For instance, offering healthier food 
options in vending machines and providing written information regarding health meals, using peer influence through clubs and other activities. As non-obese is more likely to involve in physical exercise, more facilities, and promotions for exercise are essential to control obesity in the long run. However, this could be associated some socioeconomic factors like income and other investment potentials of the area too.

The cost calculations based upon previous studies indicate that direct medical cost and total costs of obesity have increased rapidly within the period of 2001 and 2009. This highlights the importance of a comprehensive healthcare policy intervention to mitigate obesity in West Virginia.

\section{References}

[1] Finkelstein, E., Trogdon, J., Cohen, J.W. and Dietz, W. Annual medical spending attributable to obesity: Payer-and service specific estimates. Health Affairs, 28(5): 822-831, 2009.

[2] Dor, A., Ferguson, C., Langwith, C., and Tan, E. A heavy burden: The individual costs of being overweight and obese on the United States, Research Report, Department of Health Policy, School of Public Health and Health Services, The George Washington University, 2010.

[3] Malnick, S.D.H., and Knobler, H. The medical complications of Obesity, QJM 99(9): 565-579. 2006.

[4] Wolin, K.Y., Carson, K. and Colditz, G.A. Obesity and Cancer. The Oncologist 15: 556-565, 2010.

[5] Kumanyika, S.k., Obarzanek, E., Stettler N., Bell, R., Field, A.E., Formann, S.P., Franklin, B.A., Gillman, M.W., Lewis, C.E., Poston, W.C., Steven, J. and Hong, Y. Population -based prevention of obesity: The need for comprehensive promotion of health eating, physical exercise, and energy balance: A scientific statement from American Heart Association council on Epidemiology and prevention, interdisciplinary committee for prevention. Circulation 118:428-464, 2008.

[6] Gregg, E.W., Cheng, Y.J., Cadwell, B.L., Imperatore, G., Williams, D.E., Flegal, K.M., Narayan, V. and Williamson, D.F. Secular trends in cardiovascular disease risk factors according to body mass index in US adults. JAMA 293:1868-1874, 2005.

[7] Akinbami, L. The State of Childhood Asthma, United Sates, 19852005. Advanced Data from Vital and Health Statistics (No.381).Hyattsville, MD: National Center for Health Statistics, 2006.

[8] Kotchen, T. A. Obesity- related hypertension? Weighing the evidence. Hypertension 52:801, 2008.

[9] CDC. Behavioral Risk Factor Surveillance System Survey Data. U.S. Department of Health and Human Services, Atlanta, Georgia., 2009.

[10] World Health Organization [WHO]. Risk factor projects. Overweight and obesity. 2005. Retrieved from http://www.who.int/mediacentre/news/releases/2005/pr44/en/inde x.html

[11] Miljkovic, D. and Nganje, W. Regional Obesity determinants in the United States: a model of myopic addictive behavior in food consumption, Agricultural Economics 38: 375-384, 2008.

[12] Scinanama, C.N., ate, D.F., Land, W., and Wing, R.R. Who reports receiving advice to lose weight: Results from a multistate study Archive of Internal Medicine, 160(15), 2334-2339, 2000.

[13] CDC. Trends in intake of energy and macro-nutrients- United States. Morbidity and Mortality Weekly Reports, 5, 80-82, 2004.

[14] U.S. Department of Health and Services. The Surgeon General call to action to prevent and decrease overweight and obesity. Rockville, MD: U.S. Department of Health and Human Services, Office of Surgeon General, 2010.

[15] CDC. Overweight and Obesity. Retrieved September $10^{\text {th }}$ from http://www.cdc.gov/obesity/stateprograms/fundedstates/west_virgi nia.html, 2007.

[16] Pratt M, Macera C. A. and Wang G. Higher direct medical costs associated with physical inactivity, The Physician and Sportsmedicine 28: 63-70, 2000.
[17] Natalie . S.T., Suchindran, C., North, K.E., Popkin, B.M. and Larsen, P .G. Association of adolescent obesity with risk of severe obesity in adulthood. JAMA 304(18):2042-2047, 2010.

[18] U.S. Department of Health \& Human Services. .Healthy People 2010: Leading Health Indicators. 2007. Accessed December $2^{\text {nd }}$, 2011

from http://www.healthpeople.gov/Document/html/uih/uih_4.htm.

[19] Goodpaster, B. H., Delany, J.P., Otto, A.D., et al. Effects of diet and physical exercise interventions on weight loss and Cardio metabolic risk factor in severely obese adults: a randomized trial. JAMA 304(16): 1795-1802, 2010.

[20] Sabate, J. and Wien. M. Vegetarian diets and childhood obesity prevention. American Journal of Clinical Nutrition, 9(suppl): 1525s-9s, 2010.

[21] Anderson, P.M. and K. F. Butcher Childhood obesity: trends and potential causes. The Future of Children 16(1): 19-45, $2006 \mathrm{a}$.

[22] Nayga, R. M. Schooling, health knowledge and obesity, Applied Economics 32: 815-822, 2000.

[23] Cawley, J., Meyerhoefer, C. and Newhouse, D. The impacts of state physical education requirements on youth physical exercise and overweight. NBER Working Paper 11411, 2005.

[24] Appalachian Regional Commission [ARC]. Research Reports. 2008. Accesses at www.arc.gov, September 21, 2011.

[25] U.S. Census Bureau. State and county quick facts. 2011. Retrieved on September $16^{\text {th }}$ from http://quickfacts.census.gov/qfd/states/54000.html.

[26] Hammond, G. W. West Virginia Economic Outlook 2011, The Bureau of Business and Economic, College of Business and Economics, West Virginia University, P.O. Box 6025, Morgantown, wv26506-6025, 2011.

[27] Gallup. Obesity Lowest in Colorado, highest in West Virginia. 2011. Retrieved from http://www.gallup.com/poll/146534/obesitylowest-colorado-highest-west-virginia.aspx.

[28] CDC. Preventing Chronic Diseases: Investing Wisely in Health, Preventing Obesity and Chronic Diseases Through Good Nutrition and Physical exercise. 2007. Accessed December $5^{\text {th }}$, 2011 from http://www.cdc.gov/nccdphp/publications/factsheets/Prevention/o besity.htm.

[29] Amarasinghe, A., Brown, C., D’Souza and Oh, H. The Impact of County Level Factors on Obesity in West Virginia, Research paper 12.2006. www.rri.wvu.edu.

[30] Becker, G. A theory of allocation of time. 1965. The Economic Journal 75:493-517.

[31] Chou, S., Grossman, M. and Saffer, H. An economic analysis of adult obesity: Results from the behavioral risk factor surveillance system, Journal of Health Economics, 23. 565-587, 2004.

[32] CDC. Behavioral Risk Factor Surveillance System Survey Questionnaire. U.S. Department of Health and Human Services, Atlanta, Georgia. 2001.

[33] CDC. Morbidity and Mortality Wekly Report 58:45. 2009. Accessed November $15^{\text {th }}$ from www.cdc.gov/mmwr.

[34] STATA 9.1. Statistical/Data Analysis. http://www.stata.com.

[35] Tsai, A.G., Williamson, D.F.and Glick, H. A. Direct medical cost of overweight ad obesity in the USA: a quantitative systematic review, Obesity review, 12: 50-61, 2010.

[36] Finkelstein, E. A., Fiebelkon, I. C., Wang, G. National medical spending attributable to overweight and obesity: how much, and who’s paying? Health Aff: W3:219-226, 2003.

[37] Peters, A., Barendregt, J.J., Willekens, F., Mackenbach, J.P., Al Mamun, A. and L. Bonneux. Obesity in adulthood and its consequences for life expectancy: a life-table analysis. Ann Intern Med 7: 24-32, 2003.

[38] Wang, L. U., Lee, I. M., Manson, J. E., Buring, J. E. and Sesso, H. D. Alcohol Consumption, weight gain, and risk of becoming overweight in middle- aged and older women. Arch Intern Med 170(5):453-461, 2010.

[39] Drewnowski, A. and Specter, S. Poverty and Obesity: The role of energy density and energy costs. American Journal of Clinical Nutrition 79: 6-16, 2004.

[40] Centers for Medicare \& Medicaid Services. Health Expenditures by State of Residence. 2011. Retrieved from http://www.cms.gov/NationalHealthExpendData/downloads/reside nt-state-estimates.zip. 